\title{
The pseudorabies immediate early protein stimulates in vitro transcription by facilitating TFIID : promoter interactions
}

\author{
Susan M. Abmayr, ${ }^{1}$ Jerry L. Workman, and Robert G. Roeder \\ Laboratory of Biochemistry and Molecular Biology, The Rockefeller University, New York, New York 10021 USA
}

The pseudorabies virus immediate early (IE) protein, partially purified from infected HeLa cells, stimulated transcription initiation by RNA polymerase II and associated factors in HeLa nuclear extracts. This stimulation was maximal at low template concentrations, where the basal level of transcription was also low. In an analysis of the limitations on transcription under these conditions, it was found that transcription could be increased drastically not only by IE addition but also by (1) the addition of nonpromoter-containing DNA, which titrated nonspecific DNA-binding proteins in the crude nuclear extract, and (2) preincubation of the template with either the nuclear extract (in the absence of $\mathrm{Mg}^{2+}$ ) or with the TATA box-binding factor, TFIID. These results suggest that in the absence of IE, nonspecific DNA-binding proteins competed with TFIID for binding to the promoter, thus making TFIID : promoter interactions limiting for transcription. The stimulation of transcription effected by IE was essentially the same as that observed following preassociation of TFIID with the template or by titration of nonspecific DNA-binding proteins. Moreover, the presence of IE under the latter conditions did not stimulate transcription further. These observations strongly suggest that all of these manipulations affected the same limiting step and, thus, that IE accentuated the rate or extent of formation of a preinitiation complex involving the TATA factor, rather than subsequent initiation or elongation steps.

[Key Words: Immediate early; transactivation; transcription; in vitro; transcription factors; pseudorabies virus]

Received December 15, 1987; revised version accepted March 30, 1988.

Because of their relative simplicity, ease of manipulation, and utilization of cellular transcription components, the DNA viruses have been of great value in the analysis of gene regulation in animal cells. The immediate early (IE) proteins, whose synthesis early in the infectious cycle is essential for the subsequent transcription of viral genes, include the ElA protein of adenovirus, the ICP4 protein of herpes simplex virus, and the IE protein of pseudorabies virus. These proteins stimulate transcription from both cellular and viral genes under a variety of conditions (reviewed in Berk 1986). However, no promoter sequences have been identified that are uniquely involved in transcriptional stimulation. Only those sequences that also affect basal levels of transcription appear to be necessary (reviewed in Berk 1986; Coen et al. 1986; Wu et al. 1987). E1A does not bind specifically to DNA (Ferguson et al. 1985; Ko et al. 1986) and although ICP4 has been reported to bind to

'Present address: Department of Biochemistry and Molecular Biology, Harvard University, Cambridge, Massachusetts 02138 USA.
DNA, there is no evidence that this binding is related to transcriptional stimulation (Kristie and Roizman 1986a,b; Muller 1987). In addition, other studies have indicated that IE proteins overlap in function, because they can substitute for each other in vivo (Feldman et al. 1982; Tremblay et al. 1985).

Thus, these observations have led to the suggestion that viral IE proteins act through basic transcription factors, either by increasing the level of a limiting factor or by modifying an existing factor to alter its activity (reviewed in Kingston et al. 1985). The latter possibility has been supported by several experimental results. Studies with a temperature-sensitive pseudorabies IE protein demonstrated that it could stimulate transcription in a cell-free system, indicating that it did not simply increase the concentration of a factor in vivo (Abmayr et al. 1985). This possibility is also supported by recent results, demonstrating that a bacterially produced E1A protein stimulated in vitro transcription when added to HeLa cell extracts (Spangler et al. 1987). Finally, E1A expression during adenovirus infection was 
shown to increase the binding activity of an EII promoter-specific factor (Kovesdi et al. 1986a,b).

We previously developed an in vitro system derived from human 143 cells to examine transcriptional stimulation by the PrV IE protein (Abmayr et al. 1985). In this system, stimulation by IE occurred on all RNA polymerase II promoters tested, was maximal at low concentrations of exogenously added DNA template, and was temperature sensitive when prepared from a virus strain carrying a temperature-sensitive mutation in IE. We now show that partially purified IE protein from PrV-infected HeLa cells behaved similarly to the IE protein produced in 143 cells. In addition, mechanistic studies have suggested that the role of IE in stimulating transcription was to facilitate the formation of TFIID : DNA complexes.

\section{Results}

\section{Stimulation of transcription by partially purified IE from infected HeLa cells}

We have shown previously that the IE protein produced by $\operatorname{PrV}$ infection of monolayer 143 cells stimulated transcription by RNA polymerase II in vitro. The in vitro system has now been adapted to utilize HeLa spinner cells in order to obtain larger amounts of material. As reported previously for the 143 cell-derived IE protein, transcriptional stimulation by the HeLa cell-derived IE protein was maximal at low concentrations of exogenously added DNA template and was not gene specific (Abmayr et al. 1985; data not shown). HeLa cell-derived IE protein also eluted from DEAE-cellulose with $0.2 \mathrm{M}$ $\mathrm{KCl}$, and this fraction stimulated transcription from the adenovirus major late promoter in a crude nuclear extract from uninfected $\mathrm{HeLa}$ cells under conditions described in Methods (Fig. 1A, lane 1 vs. lane 3). Thus, the IE protein produced in HeLa cells was identical to that produced in 143 cells, with respect to transcriptional stimulation and chromatographic behavior on DEAEcellulose. The sole difference between these proteins was that the IE protein produced in HeLa cells did not undergo the degradation seen previously in extracts from 143 cells (Abmayr et al. 1985; Abmayr 1987).

To demonstrate that transcriptional stimulation was dependent on the presence of the IE protein, our previously described temperature inactivation assay was employed (Abmayr et al. 1985). This assay utilized tsG, a virus strain carrying a temperature-sensitive mutation in the IE protein (Ihara et al. 1983). DEAE-cellulose fractions containing the IE protein from wild-type $\operatorname{PrV}$ or ts $\mathrm{s}$ and the comparable fraction from mock-infected cells were heated at $45^{\circ} \mathrm{C}$ for $5-10 \mathrm{~min}$. Crude nuclear extract from uninfected HeLa cells was then added and the samples were assayed as usual. As shown in Figure 1A, the untreated $0.2 \mathrm{M} \mathrm{KCl}$ fraction from tsG-infected HeLa cells also had stimulatory activity (lane 2 vs. lane 3 ). However, although heat treatment of the fraction containing wild-type IE did not affect its stimulatory activity (lane 1 vs. lane 4 ), similar heat treatment of fractions from tsG-infected cells inactivated the stimulatory activity (lane 2 vs. lane 5). These results therefore demonstrated that the stimulatory activity in HeLa cell extracts was due to the IE protein.

Further purification of IE demonstrates that IE is not limiting at high template concentrations

The large amounts of extracts available from HeLa cells grown in spinner culture facilitated further purification of IE and its separation from essential transcription factors. The IE-containing $0.2 \mathrm{~m} \mathrm{KCl} \mathrm{DEAE-cellulose}$ fraction was subjected to further fractionation on phosphocellulose. Step fractions were eluted sequentially with buffers containing $0.3,0.5$, and $1.0 \mathrm{M} \mathrm{KCl}$. The stimulatory activity cofractionated with the immunoreactive IE protein and was detected primarily in the $0.3 \mathrm{M}$ $\mathrm{KCl}$ step fraction (Abmayr 1987).

In addition to assaying stimulatory activity in the 0.3 $\mathrm{M} \mathrm{KCl}$ fraction, it was necessary to assay this fraction for the presence of transcription factors in a complementation assay. None of the essential basic transcription factors elute from phosphocellulose with $0.3 \mathrm{M} \mathrm{KCl}$ (Matsui et al. 1980; Dignam et al. 1983b). To ensure that the phosphocellulose IE fraction was free of basic transcription factors, the $0.3 \mathrm{M} \mathrm{KCl}$ step fraction was assayed by reconstitution with a subset of partially purified transcription factors, as described previously (Sawadogo and Roeder 1985a). In this analysis, no transcription was detected when any of the basic factors were replaced with the IE fraction (data not shown). Thus, this $0.3 \mathrm{M} \mathrm{KCl}$ fraction could not even partially substitute for any of the required basic transcription factors, demonstrating that (1) it is essentially free of such factors, (2) any undetectable amounts of contamination could not account for the levels of transcription observed, and (3) the immediate early fraction did not contain an IE-activated basic transcription factor.

As shown previously, using extracts from PrV-infected 143 cells, transcriptional stimulation by IE was extremely sensitive to the concentration of exogenously added template DNA in the in vitro assay. Because the extracts and fractions originally used as the source of IE protein were quite impure, the level of IE could not be increased significantly without becoming inhibitory. Therefore, it was not possible to determine whether the template concentration dependence was due to limiting amounts of IE in the assay. However, the more purified phosphocellulose IE-containing fraction could be increased in the assay without becoming inhibitory. Figure 1B shows a titration of IE protein, purified through both DEAE-cellulose and phosphocellulose, at DNA template concentrations of $2 \mu \mathrm{g} / \mathrm{ml}$ and $8 \mu \mathrm{g} / \mathrm{ml}$ (lanes $1-8$ and 9-16, respectively). A clear stimulation was observed at the lower DNA concentration and at the lowest IE concentration tested (cf. lanes 1 and 5). Moreover, the level of stimulation was unaltered by an increase in the amount of IE protein (cf. lanes 1 and 4). In contrast, at the higher DNA concentration, very little stimulation was observed, even when the maximum amount of IE-containing fraction was added (cf. lanes 12 

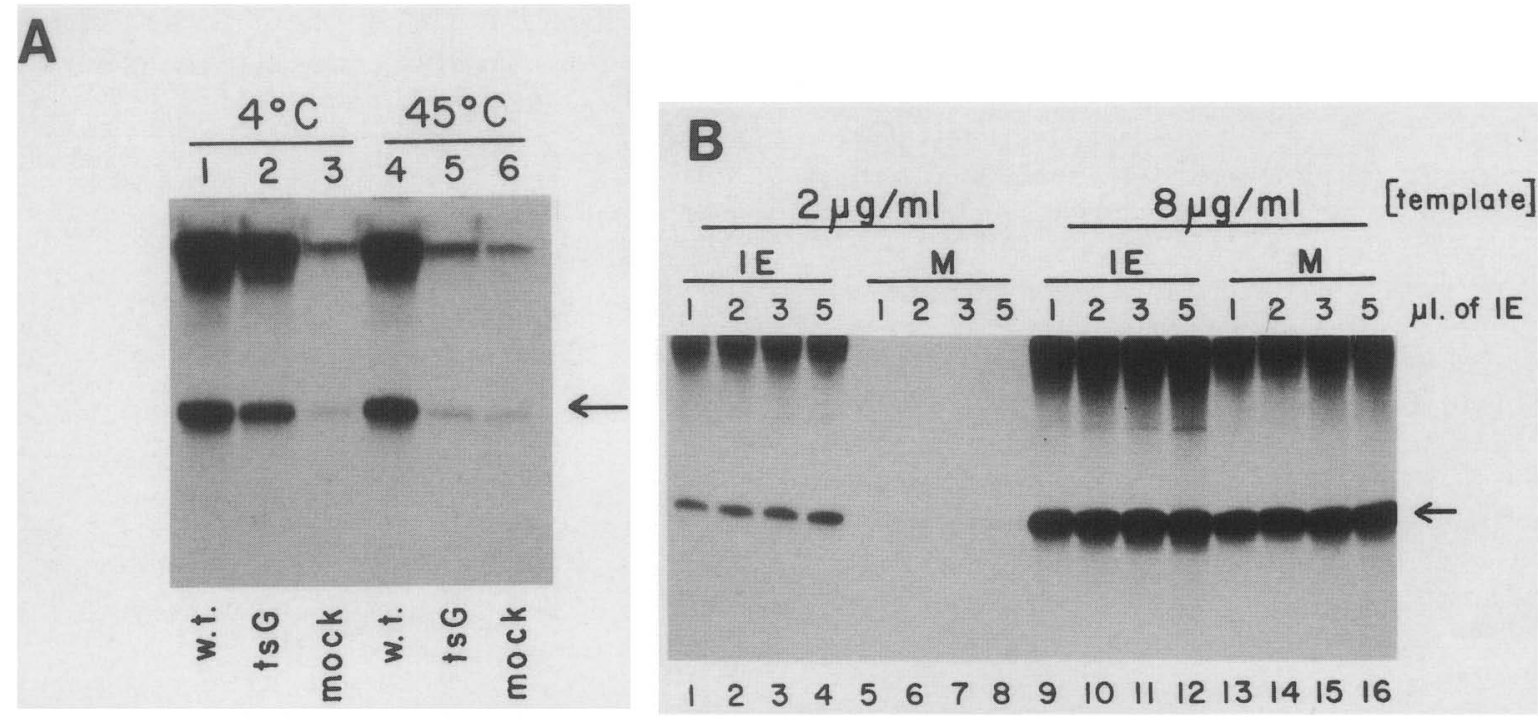

Figure 1. Transcriptional stimulation by HeLa-derived IE protein. $(A)$ The IE-containing $0.2 \mathrm{M} \mathrm{KCl} \mathrm{step} \mathrm{fractions} \mathrm{from} \mathrm{DEAE-cellu-}$ lose chromatography of extracts from wild-type-infected (lanes 1 and 4), tsG-infected (lanes 2 and 5) and mock-infected (lanes 3 and 6) HeLa cells were assayed for stimulatory activity in a runoff transcription assay. The amounts of protein used in the reactions were $12.5,10$, and $13 \mu \mathrm{g}$ from the wild-type IE, tsG IE, and mock-infected fractions, respectively. The major late promoter was used as the template, at a concentration of $2 \mu \mathrm{g} / \mathrm{ml}$. In lanes $1-3$, the fractions were kept at $4^{\circ} \mathrm{C}$ until the start of the transcription reaction at $30^{\circ} \mathrm{C}$, as described in Methods. To demonstrate that the observed stimulation was due to the IE protein, the fractions in lanes $4-6$ were incubated at $45^{\circ} \mathrm{C}$ for $10 \mathrm{~min}$ to inactivate the temperature-sensitive IE protein prior to the start of the transcription reaction. $(B)$ Varying amounts of the IE-containing $0.3 \mathrm{M}$ phosphocellulose step fraction and the comparable fraction from mock-infected cells were added to an in vitro transcription assay at two DNA template concentrations. (Lanes $1-8) 2 \mu \mathrm{g} / \mathrm{ml}$ of the Ad2 major late promoter; (lanes 9-16) $8 \mu \mathrm{g} / \mathrm{ml}$ of the Ad2 major late promoter; (lanes 1-4 and 9-12) increasing amounts of the phosphocellulose $0.3 \mathrm{M}$ step fraction from infected cells $(1,2,3$, and $5 \mu l$ of this fraction contained $0.75,1.5,2.25$, and $3.75 \mu \mathrm{g}$ of protein, respectively). (Lanes $5-8$ and 13-16) Increasing amounts of the comparable fraction from uninfected cells $(1,2,3$, and $5 \mu l$ of this fraction corresponded to 0.7 , $1.4,2.1$, and $3.5 \mu \mathrm{g}$ of protein, respectively). The samples were assayed with the addition of a fixed amount of nuclear extract from uninfected HeLa cells, as described in Methods. Quantitation was done by densitometric scanning of the autoradiogram. The ratio of signals in infected/mock-infected fractions was not obtainable at the low DNA template concentration because accurate measurements of the mock-infected samples were not possible. However, a 10-fold stimulation of transcription is a minimum estimate. At 8 $\mu \mathrm{g} / \mathrm{ml}$ of template, however, the ratios were lanes $9 / 13=0.96$, lanes $10 / 14=1.36$, lanes $11 / 15=1.34$, and lanes $12 / 16=1.37$.

and 16). These data demonstrate that the level of stimulation was dependent on the template concentration and that this was not a function of limiting amounts of IE in the assay.

\section{Titration of inhibitors with nonspecific DNA increases transcription in the absence of IE}

As shown in Figure 1B, the level of transcription observed in the presence of IE increased with increasing DNA template concentration. However, this was less than the increase observed in the absence of IE (cf. lanes 1 and 9 vs. lanes 5 and 13). Two possible mechanisms are consistent with these data. In the first case, the association of a limiting factor with the DNA template might occur more slowly, or to a lesser extent, if both the promoter and the factor are present in low concentrations. IE might facilitate this interaction by modification of the factor. At high DNA concentrations, which favor association by increasing the concentration of promoters, the effect of IE might be less apparent. If this model were correct, the addition of nonpromoter-containing (plasmid) DNA to the reaction should have no effect.

Alternatively, nonspecific DNA-binding proteins in the crude extract might compete with transcription factors for binding to the template. Removal of these nonspecific DNA-binding proteins from promoter regions by additional DNA would decrease their negative effect. In this case, IE could either directly eliminate the inhibitors or modify factors to compete more effectively (e.g., via an increased affinity). If this model were correct, the addition of nonspecific plasmid DNA should titrate the inhibitors as successfully as an increase in promoter-containing DNA.

To determine whether promoter concentration per se was responsible for the dependence of stimulation on DNA concentration, nonspecific plasmid DNA was added to the reaction. As shown in Figure 2, the addition of nonspecific plasmid DNA resulted in marked increases in the levels of transcription observed in the control and mock-infected samples (cf. lanes 1 and 3 with lanes 4 and 6 , respectively). These levels were close to those seen in the presence of IE in the absence of plasmid DNA (lane 2). Moreover, little additional stimulation occurred with the addition of nonspecific DNA to the sample containing IE (lane 5), suggesting that both the removal of inhibitors by titration with DNA and the addition of IE ultimately affected the same limiting step. If nonspecific DNA and IE were affecting different lim- 


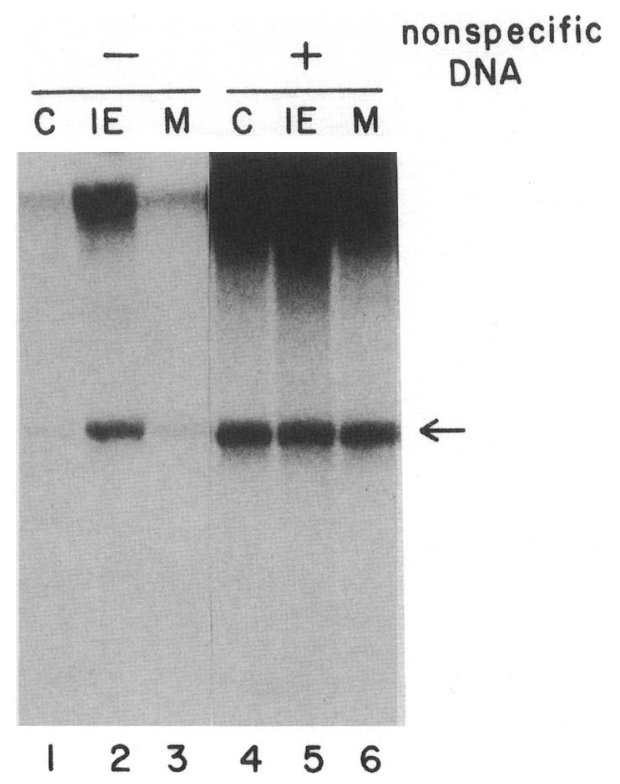

Figure 2. Effect of plasmid DNA on in vitro transcription in the presence and absence of IE. Transcription reactions were carried out under standard conditions. In all samples, the specific DNA template was the Ad2 major late promoter, at a concentration of $2 \mu \mathrm{g} / \mathrm{ml}$. [Lanes 1 and $4(C)]$ Nuclear extract from uninfected HeLa cells; [lanes 2 and $5(I E)]$ nuclear extract from uninfected HeLa cells plus $4.6 \mu \mathrm{g}$ of the IE-containing fraction, which was step eluted from phosphocellulose at $0.3 \mathrm{M} \mathrm{KCl}$; [lanes 3 and $6(M)$ ] nuclear extract from uninfected HeLa cells plus $4.6 \mu \mathrm{g}$ of the mock-infected fraction, which was step eluted from phosphocellulose at $0.3 \mathrm{M} \mathrm{KCl}$. Circular plasmid DNA from the bacterial cloning vector $\mathrm{pUC} 12$ was added to the samples in lanes $4-6$ to a final concentration of $2 \mu \mathrm{g} / \mathrm{ml}$.

iting steps in transcription initiation, the activity observed in lane 5, with both IE and plasmid DNA present, would have been a summation of the individual stimulatory effects. That these inhibitory proteins exhibit no sequence specificity was further demonstrated by the fact that both poly $(\mathrm{dA}: \mathrm{dT} / \mathrm{dT}: \mathrm{dA})$ and poly $(\mathrm{dG}: \mathrm{dC} /$ $\mathrm{dC}: \mathrm{dG}$ ) titrated these inhibitors as efficiently as plasmid DNA at the same concentrations /data not shown).

It is of interest to note that the nonspecific initiated transcription (seen at the top of the lanes) is also stimulated by IE. However, this is not surprising because this transcription is also mediated by RNA polymerase II and, furthermore, requires all the basic factors necessary for specific initiation (see Sawadogo and Roeder 1985a). This transcription most likely originates from transcription complex formation on TATA-like sequences within the pUC vector. This accounts for the more dramatic increase in the transcription seen by the addition of pUC (i.e., by an increase in their concentration) than by the addition of IE (Fig. 2) or alternating homopolymer DNAs (data not shown).

One trivial explanation for the stimulation by nonspecific DNA is that nucleases, which might have been present in the crude extract, altered the DNA so that it could no longer be an adequate template for transcrip- tion. In this case, the addition of nonspecific DNA might have relieved digestion of at least some of the template. However, incubation of radioactively labeled, covalently closed, plasmid DNA with crude extracts and with fractions from infected and mock-infected cells, under the conditions used for transcription, did not result in significant digestion of the plasmid. In addition, the nicking of the plasmid was approximately the same for infected and mock-infected samples /data not shown). This result, therefore, is inconsistent with the 'inhibitors' simply being nucleases and suggests that they are DNA-binding proteins.

These data indicate that the presence of nonspecific DNA-binding proteins was critical to the observation of IE-mediated stimulation of transcription. Extracts from uninfected cells were able to effect the same level of transcription as that observed in the presence of IE once these nonspecific DNA-binding proteins were removed. Thus, neither the concentration of transcription factors nor promoters was limiting in the absence of IE. Rather, these data indicate that the accessibility of promoters to transcription factors was restricted by nonspecific DNA-binding proteins. This conclusion is also consistent with the observation that IE-mediated stimulation was difficult to observe in assay systems reconstituted with partially purified transcription factors, presumably because the concentration of nonspecific DNA binding proteins was decreased through chromatography (data not shown). As a result, the transcription assay employed may have been inadequate to detect any IE-dependent modification of factor interactions (see Discussion). An alternative possibility is that other intermediates required for IE action were lost during factor purification.

Preincubation of extract and DNA template stimulates transcription and precludes the effect of IE

It has been known for some time that transcription exhibits linear kinetics in nuclear extracts but only after a brief initial lag (Dignam et al. 1983a). Preincubation of the extract and DNA prior to the start of transcription appeared to decrease or eliminate this lag, significantly increasing the subsequent level of transcription (Fire et al. 1984; J.D. Dignam and R.G. Roeder, unpubl.). Thus, the lag presumably reflected a rate-limiting step in the association of transcription factors with the DNA.

To address the possibility that the rate of association of transcription components was altered in the presence of IE, we conducted a series of studies in which the DNA template was preincubated with nuclear extract prior to the start of transcription. In comparison to the abovementioned kinetic studies that were conducted at high template concentrations, preincubation was carried out at low DNA concentrations both under similar conditions (with $\mathrm{Mg}^{2+}$ ) and in the absence of $\mathrm{Mg}^{2+}$. As shown in Figure 3A, preincubation of extract and DNA template in the absence of $\mathrm{Mg}^{2+}$ significantly increased the subsequent level of transcription in the mock-infected samples (cf. lanes 2 and 4). As a result, transcription in 


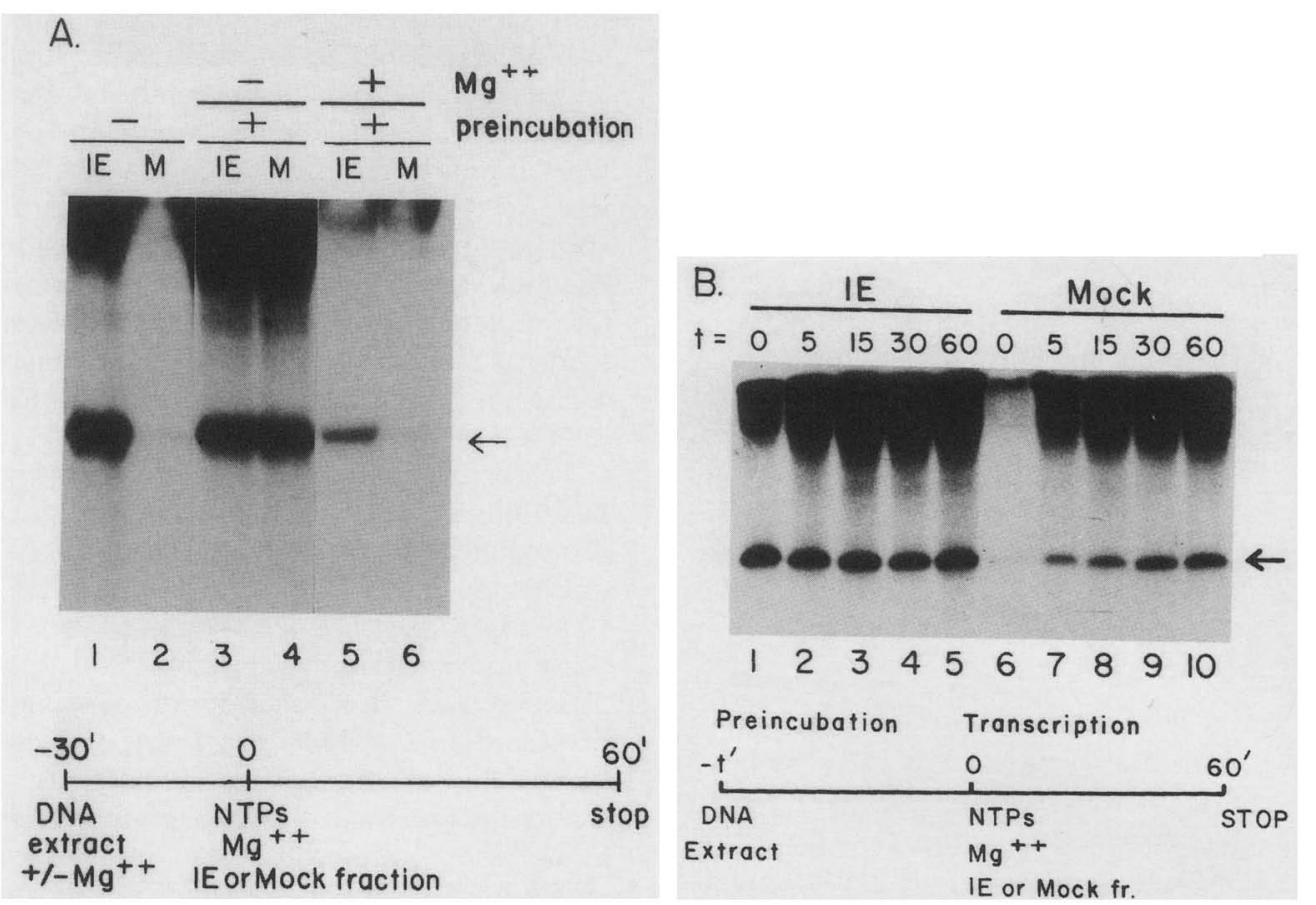

Figure 3. Preincubation of template and extract prior to the addition of IE and the start of transcription. $(A)$ Crude nuclear extract from uninfected HeLa cells was preincubated with the DNA template as illustrated schematically. Preincubation conditions for lanes 3 and 4 were $100 \mathrm{~mm} \mathrm{KCl}, 20 \%$ glycerol, $20 \mathrm{~mm}$ HEPES (pH 7.9), 1 mM EDTA, and $0.5 \mathrm{mM}$ DTT. Preincubation conditions for lanes 5 and 6 included $10 \mathrm{mM} \mathrm{MgCl}_{2}$ but were otherwise identical. Lanes 1 and 2 were not preincubated. The Ad2 major late promoter was the DNA template. In all samples, the template DNA concentration was $\sim 6 \mu \mathrm{g} / \mathrm{ml}$ in the preincubation, to give a final concentration of 2 $\mu \mathrm{g} / \mathrm{ml}$ in the transcription reaction. After the preincubation, partially purified IE protein from DEAE-cellulose chromatography of HeLa cell extracts and the comparable fraction from mock-infected HeLa cells were added. The transcription reaction was started with the addition of a reaction cocktail containing nucleoside triphosphates and $\mathrm{MgCl}_{2}$ was added to bring the final concentration in each transcription to $10 \mathrm{mM}$. This dilution also decreased the salt and glycerol concentrations to the standard conditions of $60 \mathrm{~mm}$ $\mathrm{KCl}$ and $12 \%$ glycerol. The transcription reaction proceeded for $60 \mathrm{~min}$ at $30^{\circ} \mathrm{C}$, as usual. $(B)$ Crude nuclear extract from uninfected HeLa cells was preincubated with the DNA template for various periods of time at $30^{\circ} \mathrm{C}$ in the absence of $\mathrm{Mg}^{2+}$ prior to the start of transcription. Preincubation conditions were $100 \mathrm{mM} \mathrm{KCl}, 20 \%$ glycerol, $20 \mathrm{mM}$ HEPES (pH 7.9), 1 mM EDTA, and $0.5 \mathrm{mM}$ DTT. Assay conditions were as described in $A$, with the exception that crude nuclear extracts from infected and mock-infected 143 cells were used as a source of IE.

the absence of IE was increased to virtually the same level as that observed in the presence of IE (cf. lanes 1, 3, and 4). Furthermore, this level was the same even when IE was included during the preincubation, rather than added subsequently (data not shown). In contrast, and importantly, preincubation of the DNA template and extract in the presence of $\mathrm{Mg}^{2+}$ ions did not elevate the subsequent level of transcription in the mock-infected sample (cf. lanes 2 and 6). In fact, preincubation under these conditions significantly inhibited stimulation upon the subsequent addition of IE (cf. lanes 1, 3, and 5). These results suggest that preincubation of the DNA template with extract in the absence of $\mathrm{Mg}^{2+}$ favored the association of transcription components, whereas preincubation in the presence of $\mathrm{Mg}^{2+}$ favored association of the nonspecific DNA-binding proteins discussed previously.

The suggestion that the IE protein stimulated transcription by facilitating the rate of association of transcription components, thereby eliminating the effect of preincubation in the absence of IE, is further supported by the experiment shown in Figure 3B. In this experi- ment, the DNA template and extract were preincubated for various lengths of time at $30^{\circ} \mathrm{C}$ in the absence of $\mathrm{Mg}^{2+}$ before allowing transcription. As shown in lanes 6-10, the subsequent level of transcription in the absence of IE was increased significantly with increasing times of preincubation, consistent with the slow association of factors with the DNA template. In contrast, the level of transcription was high in the presence of IE, independent of the length of time of the prior preincubation (lanes 1-5). Thus, under conditions that alleviate the binding of nonspecific proteins and permit the slow association of transcription components, the nuclear extract is capable of attaining a level of transcription in the absence of IE that is comparable to that seen in the presence of IE. The IE protein apparently accelerates this rate-limiting step, resulting in an increased rate of formation of transcription complexes. This result supports the basic conclusions of Leong and Berk (1986) that more transcription complexes may be formed in the presence of E1A. However, in the absence of kinetic data, these investigators could not address the possibility that E1A was actually affecting the rate of complex formation. 
The preincubation results described above (Fig. 3A) have been reproduced with several different nuclear extract preparations from uninfected HeLa cells and with partially purified IE-containing or mock-infected DEAE-cellulose and phosphocellulose fractions from HeLa cell nuclear extracts. In addition, both the Ad2 EIII promoter and the mouse $\beta$-globin promoter, shown previously to be stimulated by IE in vitro (Abmayr et al. 1985), have been examined. Preincubation of templates containing these promoters with nuclear extract (in the absence of $\mathrm{Mg}^{2+}$ ) similarly stimulated subsequent transcription and precluded further stimulation by the addition of IE.

Preincubation of the DNA template with transcription factor TFIID both mimics the stimulatory effect of IE and precludes further stimulation by IE

The previous results are consistent with the possibility that IE altered the efficiency or stability of the binding of one or more of the transcription factors, so that a slow step in formation of transcription complexes was better able to compete with a more rapid step involving inhibitory interactions of nonspecific DNA-binding proteins. To better understand the limiting step that was overcome by either preincubation or the presence of IE, the template was preincubated with isolated transcription factors to determine which factor(s) was responsible for the increase in transcription that was observed after preincubation. Preincubation was followed by the addition of crude extract, partially purified IE protein, nucleotides, and divalent cations. As shown in Figure 4A, the addition of fractions containing TFIIB, E, or A to the crude extract neither increased the level of transcription in the absence of IE nor eliminated the requirement for IE, either with or without preincubation. In fact, preincubation with factors TFIIB and TFIIE actually decreased transcription, most likely due to inhibitory proteins in the preparations.

In contrast, preincubation with phosphocellulose (P11) or more highly purified DEAE-cellulose (DE52) fractions containing TFIID clearly increased transcription in the absence of added IE (Fig. 4B, lane 2 vs. lane 4). Interestingly, the level of specific transcription was not increased significantly by the addition of IE after preincubation with TFIID (lane 1 vs. lane 2). In control reactions without preincubation, the IE preparation stimulated transcription markedly, either with (lane 3 vs. lane 4) or without (lane 5 vs. lane 6) added TFIID.

To address the possibility that small amounts of contaminating basic factors might be contributing to the effects of the TFIID fractions, these preparations of TFIID were tested for cross-contamination by reconstitution with the other factors (Sawadogo and Roeder 1985a). Although the P11 TFIID fraction contained trace amounts of contaminating factors, the DE52 TFIID fraction was found to be free of any detectable contaminating factors (data not shown). Thus, the elevation of transcription achieved after TFIID : template preincubation was due to TFIID and not dependent on contaminating basic factors, because their concentrations were insufficient to effect the levels of transcription observed.

These data demonstrate that at low template concentrations transcription is limited by inhibition of TFIID : promoter interactions by components of the $\mathrm{HeLa}$ nuclear extract. However, this inhibition is avoided by the prior exposure of the template DNA to the TFIID factor. Furthermore, once transcription factor TFIID had bound to the promoter, IE was no longer required for maximum transcription and was not able to stimulate transcription further. Both DNA and partially purified TFIID were required during the preincubation for this increase. Preincubation of DNA alone or TFIID containing fraction alone had no effect (data not shown).

\section{Only core promoter sequences are necessary for stimulation by IE}

In vivo analysis with promoter mutations has shown that no specific sequences are uniquely required for stimulation by IE proteins (reviewed in Berk 1986). In addition, several promoters have been analyzed in the in vitro transcription system, and, as expected, they were all stimulated by IE (Abmayr et al. 1985). These results, then, are consistent with the model that IE acts through basic transcription factors and core promoter sequences. To demonstrate directly that gene-specific sequences were not required, we have analyzed mutations of the Ad2 major late promoter for their ability to be stimulated by IE. As shown in Figure 5, the removal of sequences surrounding the TATA sequence had a dramatic effect on the level of transcription from this promoter. These sequences included the binding site $(-63$ to -52$)$ of USF, the major late specific transcription factor $(\mathrm{Sa}$ wadogo and Roeder 1985b), which was deleted in the mutations analyzed in lanes 7-10. They also included sequences located downstream of the TATA sequence near the cap site, which were deleted in the mutations analyzed in lanes 1 and 2 . In each type of mutant, the basal level of transcription was reduced significantly compared with the wild-type promoter (lanes 5 and 6), in good agreement with the studies of $\mathrm{Hu}$ and Manley (1981). However, transcription from all of the templates was stimulated by the addition of IE. Neither the USFbinding site nor the downstream sequences were absolutely required for stimulation by IE. Thus, this result is consistent with the previous observations implicating the TATA box-binding factor, TFIID, as the likely site of action of IE.

\section{Discussion}

The IE protein of pseudorabies virus and similar proteins from other double-stranded DNA viruses increase transcription from a variety of promoters in vivo (reviewed in Kingston et al. 1985; Berk 1986). Our previously described cell-free transcription system, consisting of a nuclear extract from uninfected HeLa cells complemented with a partially purified pseudorabies IE protein (Abmayr et al. 1985), accurately reproduces this effect in 

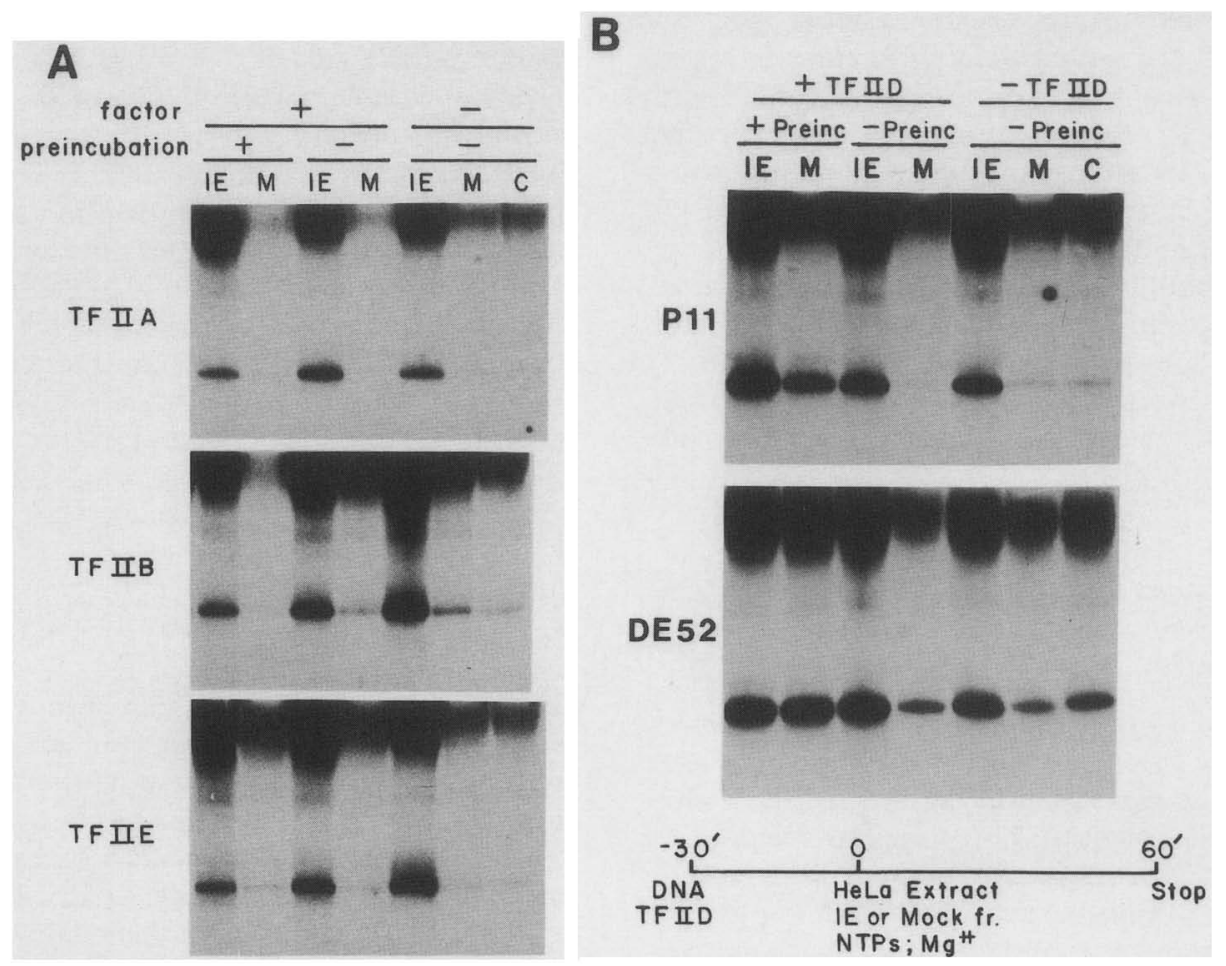

Figure 4. Preincubation of template and partially purified transcription factors prior to the addition of IE and the start of transcription. (A) Partially purified preparations of transcription factors TFIIA, TFIIB, and TFIIE, prepared as discussed in Methods, were preincubated with the DNA template in the absence of $\mathrm{Mg}^{2+}$. Conditions of preincubation were as described in Figure 3, except that the DNA template concentration was $8.3 \mu \mathrm{g} / \mathrm{ml}$ during the preincubation, to give a final concentration of $2 \mu \mathrm{g} / \mathrm{ml}$ in the transcription reaction. After the preincubation, extract from uninfected HeLa cells was added to supply the other transcription factors. Partially purified IE protein from DEAE-cellulose chromatography of HeLa cell extracts $(0.75 \mu \mathrm{g})$ and the comparable fraction from mock-infected HeLa cells $(0.7 \mu \mathrm{g})$ were added. The transcription reaction was started with addition of the reaction cocktail, and the samples were incubated at $30^{\circ} \mathrm{C}$ for $30 \mathrm{~min}$. The Ad2 major late promoter was the DNA template. For TFIIA, each sample contained $5 \mu l$ of a DEAE-cellulose fraction, which was $4.27 \mathrm{mg} / \mathrm{ml}$ protein plus $0.5 \mathrm{mg} / \mathrm{ml} \mathrm{BSA}$. For TFIIB, each sample contained $3.2 \mu \mathrm{g}$ of protein from DEAE-cellulose. For TFIIE, each sample contained $3 \mu \mathrm{g}$ of protein from DEAE-cellulose. (B) In the upper panel (P11), $5 \mu \mathrm{g}$ of transcription factor TFIID, from a phosphocellulose $0.8 \mathrm{M} \mathrm{KCl}$ step fraction, was preincubated with the DNA template at $30^{\circ} \mathrm{C}$ for 30 min, as indicated. Conditions for preincubation and transcription were as in Figure 4A. Partially purified IE protein from DEAE-cellulose chromatography of HeLa cell extracts $(0.75 \mu \mathrm{g})$ and the comparable fraction from mock-infected HeLa cells $(0.7 \mu \mathrm{g})$ were added. The Ad2 major late promoter, at a final concentration of $2 \mu \mathrm{g} / \mathrm{ml}$ in the transcription reaction, was the DNA template. In the lower panel (DE52), the DNA template was preincubated with TFIID, which had been purified through both phosphocellulose and DEAEcellulose as described in Methods. In each sample, $5 \mu$ l of a fraction that had $0.52 \mu \mathrm{g} / \mu \mathrm{l}$ of protein and $0.5 \mu \mathrm{g} / \mu \mathrm{l}$ of added BSA was used. The IE-containing fraction had been purified through both DEAE-cellulose and phosphocellulose; 0.92 and $1.08 \mu \mathrm{g}$ from infected and mock-infected fractions, respectively, were used. The DNA template concentration was $14 \mu \mathrm{g} / \mathrm{ml}$ in the preincubation, to give a final concentration of $4 \mu \mathrm{g} / \mathrm{ml}$ in the transcription reaction. All other conditions were as in the upper panel. Quantitation of the lower panel was done by densitometric scanning of the autoradiogram. In arbitrary densitometric units, the signals for lanes 1-7 (left to right) were $7.7,7.1,8.6,2.2,6.2,2.0$, and 3.1.

vitro. That the in vitro effects of IE are related to its in vivo function is indicated by the fact that stimulation of transcription by the temperature-sensitive IE protein from the tsG virus (Ihara et al. 1983) was inactivated similarly at the nonpermissive temperature $\left(42^{\circ} \mathrm{C}\right)$, both in vitro and in vivo, whereas the function of the wildtype protein was not affected in either situation.

In the present analysis, the ability to generate larger amounts of undegraded wild-type and tsG IE proteins from virus-infected HeLa cells has allowed us to further purify and analyze the mechanism of IE action. Studies with the wild-type IE protein allowed us to demonstrate clearly that transcriptional stimulation in vitro was not due to contaminating cellular transcription factors and that IE was not limiting at the high template concentrations at which the basal level of transcription was elevated and no stimulation by IE was apparent (see further discussion below). Similarly, studies with the more purified tsG IE protein confirmed that the transcriptional stimulation was dependent upon functional IE and, with the other analysis, substantiated the previous conclusion that IE stimulation was mediated via preexisting cellular factors. Using the modified in vitro system, we have analyzed the IE-mediated transcriptional stimulation further and have deduced the limiting step at which IE acts. 


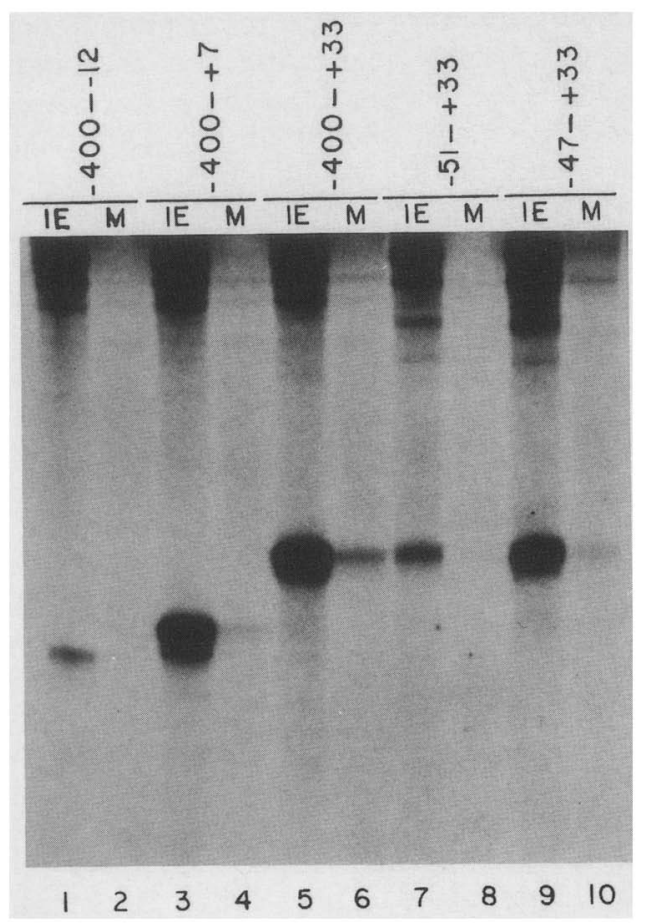

Figure 5. Transcriptional analysis of mutations of the Ad2 major late promoter. Transcription reactions were carried out under standard conditions, as described in Methods. The BamHI-digested DNA templates were pHB222 (lanes 1 and 2), pHB306 (lanes 3 and 4), p $\phi 4$ (lanes 5 and 6), pXB806 (lanes 7 and 8 ), and pXB801 (lanes 9 and 10), which were described by $\mathrm{Hu}$ and Manley (1981). The portion of the major late promoter (relative to the cap site) contained in each construct is indicated. In all samples, the DNA template concentration was 4 $\mu \mathrm{g} / \mathrm{ml}$. Either $3.9 \mu \mathrm{g}$ of an IE-containing DE52 fraction from infected HeLa cells or $4.1 \mu \mathrm{g}$ of the comparable DE52 fraction from mock-infected HeLa cells was added to each reaction, as indicated.

\section{The IE protein increases the efficiency of formation of} a TFIID : DNA complex

To deduce the site and mechanism of IE action, we have examined the limitations on transcription under conditions where the stimulatory effect of the IE protein was maximal. As shown previously, this stimulation was observed only when the basal level of transcription in the nuclear extract was decreased by lowering the template concentration. Under these conditions, transcription was limited by the rate or extent of association of cellular transcription factors with the template. This was evidenced by the observations that transcription in nuclear extracts at low template concentrations (in the absence of IE) could be increased markedly (1) by titration of the extract with nonpromoter-containing DNAs, indicating that the inhibition of factor: promoter interactions was mediated by nonspecific DNA-binding proteins and (2) by allowing interactions (and stable binding, see below) of transcription factor TFIID with the promoter before exposure to the nuclear extracts containing the nonspecific binding proteins. Thus, the presence of nonspecific DNA-binding proteins in the nuclear extract makes TFIID : promoter interactions limiting for transcription at low template concentrations, although neither TFIID nor the overall promoter concentration is limiting. It was also observed that IE no longer stimulated transcription when TFIID : promoter interactions preceded transcription in the extract or when nonspecific DNA-binding proteins were titrated with nonpromoter-containing DNAs. In fact, the level of transcription observed in these latter cases was equivalent to the level observed under normal transcription conditions in the presence of IE. These results support the conclusion that IE addition affects, ultimately, the same limiting step affected by the other manipulations. More specifically, they indicate clearly that IE was acting at the level of preinitiation complex formation, either prior to or directly at the TFIID-binding step and not subsequent initiation or elongation steps.

TFIID is the factor responsible for recognition of the TATA box, and footprint analysis has shown that it binds to this region of the promoter in the absence of other transcription factors (Sawadogo and Roeder 1985b; N. Nakajima, M. Horikoshi, and R.G. Roeder, unpubl.). Binding of TFIID to the TATA box is one of the first steps in formation of a template-committed stable complex, and this association appears to be favored by preincubation of the template and factor (Fire et al. 1984; Reinberg et al. 1987). This complex is most likely analogous to the template-committed complex that was defined by Hawley and Roeder $(1985,1987)$. The fact that this complex has been shown to form slowly under in vitro conditions accounts for the efficient inhibition by nonspecific DNA-binding proteins observed here.

That IE alters the efficiency of TFIID binding is consistent with the fact that the sequences required to observe stimulation in vitro are also those required for basal expression. Indeed, our analysis of adenovirus major late promoter deletions has shown that stimulation in the in vitro assay does not involve sequences uniquely necessary for IE stimulation. Although some deletions affected the basal level of transcription, all constructions containing the TATA box were still stimulated by IE in the in vitro assay. These results are in good agreement with the results of Wu et al. (1987), who found that only mutations in the TATA box region of the E1B promoter interfered with transactivation by E1A in vivo.

Two possible mechanisms could account for the facilitation of TFIID : promoter interactions in the presence of IE. This might result either from a direct effect of IE (or some intermediate) on the efficiency of TFIID binding or from a more indirect effect via the inactivation by IE of nonspecific DNA-binding proteins. It is not yet possible to distinguish absolutely between these two possibilities. However, we believe the latter is unlikely because the inhibitory proteins bind with equal affinity to template, vector, or alternating homopolymer sequences. This clearly rules out the possibility that they are promoter sequence-specific repressors upon which IE might act, and it seems improbable that IE would specifically inactivate a nonspecific and likely heterogeneous 
class of DNA-binding proteins. Moreover, the IE protein only partially reverses the inhibitory effect of the nonspecific DNA-binding proteins once allowed to interact with DNA in the presence of $\mathrm{Mg}^{2+}$ (Fig. 3A). This favors the idea that IE has a more direct effect on TFIID binding and emphasizes that although the inhibitory proteins could also have an in vivo role in restricting activity, they might also be peculiar to in vitro systems. In either case, they place a restriction on activity in vitro and thus, perhaps fortuitously, allow us to measure alterations in the efficiency of TFIID binding. In this context, the present observations do not exclude the possibility that IE-mediated alterations of TFIID interactions, even occur under the various conditions where the stimulatory effect of IE was not apparent, because the transcription assay may simply not have been adequate to detect these changes. The future resolution of this question, and more direct proof of possible TFIID modifications, awaits the development of assays that can measure directly the rate of TFIID binding.

\section{The role of IE proteins in vivo}

In vivo experiments from several laboratories have indicated that the requirement for E1A is not absolute. This has been shown by the detection of early gene expression several hours postinfection with the adenovirus E1A deletion mutant dl312 and by infection of HeLa cells with dl312 at high multiplicities (Shenk et al. 1979; Nevins 1981). These results may also be explained in terms of competition between different DNA-binding proteins for the promoter, including differences in both the rates of formation and stabilities of various DNAprotein complexes. Thus, infection at high multiplicities of dl312 might result in a rapid titration of nonspecific DNA-binding proteins that prevent TFIID binding, increasing expression because of the accessibility of an excess of viral promoters. On the other hand, the ElA-independent transcription of early genes at prolonged times of infection might reflect a slower but more stable interaction of TFIID with the promoter/relative to nonspecific DNA-binding protein interactions); thus, an effective displacement of nonspecific DNAbinding proteins by TFIID /generating functional preinitiation complexes) would be apparent only after long time periods. This slow association of TFIID might also explain why transcription of delayed early genes is restricted to the primary viral template (cis effect) following superinfection at late times of infection in the absence of E1A (Gaynor and Berk 1983). Presumably, activation of the second template would require the same slow association of TFIID, independent of expression from the first template.

Recent in vitro results support the suggestion that competition between TFIID and repressing DNAbinding proteins could play a critical role in regulating promoter activity. In vitro nucleosome assembly has been shown to block transcription initiation by RNA polymerase II from assembled promoters (Knezetic and Luse 1986; Matsui 1987). However, this repression is al- leviated by the binding of TFIID to the promoter prior to nucleosome assembly, indicating that the binding of TFIID is stable to nucleosome assembly and is necessary to maintain promoter accessibility to additional transcription factors and RNA polymerase II (Workman and Roeder 1987). TFID binding may therefore be a critical step for the in vivo expression of adenovirus genes early in infection, when the core DNA is presumably uncoated and reassembled into a structure resembling cellular chromatin.

\section{Further considerations of IE mechanism}

Further functional and structural studies should establish the mechanism by which IE facilitates TFIID : promoter interactions. For instance, IE may interact stoichiometrically with TFIID and/or the promoter to accentuate the rate of TFIID binding to promoter sequences. In fact, the possibility that IE proteins may interact directly with a TFIID : promoter complex is consistent with the observation that the transcriptional activating domain of the E1A gene contains a zinc finger motif characteristic of many DNA-binding proteins (reviewed by Moran and Mathews 1987). Thus, although E1A apparently does not specifically bind DNA by itself, the DNA-binding potential of its putative zinc finger may be realized through interactions with a sequencespecific DNA-binding protein such as TFIID. Alternatively, IE proteins might act catalytically to modify TFIID to generate a more active form. E1A expression in vivo has been shown to generate a more active form of TFIIIC (an essential factor for transcription of polymerase III genes|, which is also induced by high serum concentrations (Hoeffler et al. 1988.) Thus, it is possible that the action of IE proteins, either directly or through various cellular processes, is to modify and thereby activate general transcription factors (such as TFIIIC and TFIID) that operate on core promoters. This does not exclude the possibility that IE proteins might also affect other cellular factors that act on upstream sequences, such as that previously described for the EII promoter (Kovesdi et al. 1986a,b).

Clearly this and the previous study (Abmayr et al. 1985) have demonstrated that all the steps for IE transactivation occur in vitro. Therefore, further purification and characterization of the necessary components should reveal the precise biochemical mechanism of IE action.

\section{Methods \\ Cells and viruses}

HeLa cells were maintained in suspension in Joklik's-minimal essential medium (MEM), containing $5 \%$ bovine calf serum. Pig kidney and rabbit kidney cell lines were maintained in monolayer cultures in Dulbecco's media, containing $5 \%$ fetal calf serum.

Wild-type pseudorabies virus stocks were grown from plaque-purified virus on pig kidney cells at $37^{\circ} \mathrm{C}$. ts $\mathrm{G}$ virus stocks were grown on pig kidney cells at $32^{\circ} \mathrm{C}$. Virus stocks were stored at $-80^{\circ} \mathrm{C}$ as cell lysates. Cell debris was removed 
prior to use. Virus stocks were plaqued on rabbit kidney cells at either $32^{\circ} \mathrm{C}$ or $37^{\circ} \mathrm{C}$, as appropriate. Two hundred microliters of various dilutions of virus in phosphate buffered saline (PBS) were adsorbed to confluent monolayers of RK cells $\mid 60 \times 15$ $\mathrm{mm}$ ) for $1 \mathrm{hr}$. The plates were then overlayed with $5 \mathrm{ml}$ of Dulbecco's media, plus $5 \%$ serum with $0.9 \%$ Noble agar (Difco $0142-02$ ). After $72 \mathrm{hr}$, the plates were overlayed with $5 \mathrm{ml}$ of the above media to which neutral red dye had been added. The plaque assays were scored 6-10 hr later.

\section{Plasmids}

The adenovirus major late promoter-containing plasmid is the SmaF fragment of Ad2, which has been cloned into pBR313. Accurate initiation on a plasmid linearized with SmaI generates a runoff transcript of 536 nucleotides. The promoter mutations used in the experiment of Figure 5 were a gift of Dr. J. Manley and are described in $\mathrm{Hu}$ and Manley (1981).

\section{Infection and extract preparation}

Infection, extract preparation, and chromatographic fraction to generate the IE protein from 143 cells used in Figure 3B were as described previously (Abmayr et al. 1985). All other analyses used IE protein produced in infected HeLa cells, as described below.

HeLa cells were spun at $3000 \mathrm{rpm}$ for $10 \mathrm{~min}$, washed with PBS to remove serum components, and respun. The media were retained. Pelleted cells were resuspended in virus lysate plus serum-free media at a multiplicity of infection of $\sim 5-20 \mathrm{pfu} /$ cell, with a final serum concentration of $4 \%$ or less. Virus was adsorbed for $1 \mathrm{hr}$. The cells were then diluted back to the original volume in the original media plus serum. The infection was allowed to proceed for an additional $2.5 \mathrm{hr}$ at $37^{\circ} \mathrm{C}$ for wildtype pseudorabies-infected cells and at $32^{\circ} \mathrm{C}$ for tsG-infected cells.

The cells were spun and nuclear extracts were prepared according to the procedure of Dignam et al. (1983a), except for the following modifications. The nuclei were gently dispersed in one-half packed nuclei volume of nuclear extract buffer containing only $0.02 \mathrm{M} \mathrm{KCl}$. One-half packed nuclei volume of nuclear extract buffer containing $1.4 \mathrm{M} \mathrm{KCl}$ was then added slowly, and the nuclei gently mixed. The final $\mathrm{KCl}$ concentration during the extraction was $0.35 \mathrm{M}$.

\section{Chromatographic fractionation}

Nuclear extracts from infected and mock-infected HeLa cells were initially chromatographed on DEAE-cellulose (Whatman DE52), as described previously (Abmayr et al. 1985). The columns were equilibrated in BC buffer [ $20 \mathrm{mM}$ HEPES ( $\mathrm{pH} 7.9$ ), $20 \% \mathrm{vol} / \mathrm{vol}$ glycerol, $0.2 \mathrm{~mm}$ EDTA, $0.5 \mathrm{~mm}$ dithiothreitol (DTT), and $0.5 \mathrm{~mm}$ phenylmethylsulfonyl fluoride (PMSF)], containing $0.1 \mathrm{M} \mathrm{KCl}$. Extracts of approximately equal protein concentrations (averaging $6-8 \mathrm{mg} / \mathrm{ml}$ ) and cell equivalents were loaded onto the columns and step fractions eluted in $\mathrm{BC}$ buffer containing 0.2 and $0.5 \mathrm{M} \mathrm{KCl}$. Approximately $3-5 \mathrm{ml}$ of extract, containing $6-8 \mathrm{mg} / \mathrm{ml}$ protein, was fractionated on a $3-\mathrm{ml}$ column. Fraction sizes of $\sim 400-700 \mu \mathrm{l}$ were collected.

The IE-containing $0.2 \mathrm{M} \mathrm{KCl}$ step fraction and the comparable fraction from mock-infected cells were subsequently chromatographed on phosphocellulose ion exchange columns. Again, columns were equilibrated with $\mathrm{BC}$ buffer (see above), containing $0.1 \mathrm{M} \mathrm{KCl}$. Step fractions were eluted in $\mathrm{BC}$ buffer containing $0.3,0.5$, and $1.0 \mathrm{M} \mathrm{KCl}$. The columns and input material were of variable size and amount, but routinely $1 \mathrm{ml}$ of input at
$3 \mathrm{mg} / \mathrm{ml}$ protein was loaded onto a $0.5-\mathrm{ml}$ column. Fraction sizes of $\sim 150 \mu \mathrm{l}$ were collected. Protein concentrations were assayed by the Bio-Rad protein assay, which is based on the procedure of Bradford (1976). The presence of IE protein was detected by protein blotting, as described previously (Abmayr et al. 1985; Abmayr 1987).

Partially purified transcription factors were prepared from extracts of uninfected HeLa cells. The nuclear extracts were prepared essentially by the procedure of Dignam et al. (1983a), with the same modifications discussed above. These extracts were then subjected to chromatographic fractionation by phosphocellulose ion exchange (Dignam et al. 1983b). Further purification of these factors was done according to published procedures (Dignam et al. 1983b; Slattery et al. 1983; Sawadogo and Roeder 1984), with the modifications of Sawadogo and Roeder (1985a). Briefly, the TFIIA preparation from the $0.1 \mathrm{M}$ phosphocellulose fraction was chromatographed on DEAE-cellulose. TFIIB and TFIIE, contained in the phosphocellulose $0.5 \mathrm{M} \mathrm{KCl}$ step fraction, were separated by chromatography on DEAEcellulose. The $0.8 \mathrm{M} \mathrm{KCl} \mathrm{TFIID-containing} \mathrm{step} \mathrm{from} \mathrm{phospho-}$ cellulose was chromatographed further on DEAE-cellulose. All fractions were dialyzed to BC100 buffer [20 mM HEPES (pH 7.9), $20 \% \mathrm{vol} / \mathrm{vol}$ glycerol, $0.1 \mathrm{M} \mathrm{KCl}, 0.2 \mathrm{~mm}$ EDTA, $0.5 \mathrm{~mm}$ DTT, and $0.5 \mathrm{mM}$ PMSF] prior to use. In addition, fractions were assayed by complementation in reconstituted transcription assays. By this analysis, it was found that these fractions contained only trace amounts or no detectable cross-contamination with the other transcription factors.

\section{Transcription assay}

Runoff transcription assays were performed essentially by the procedure of Dignam et al. (1983a), with the exception that $15-\mu l$ of extract and fractions were assayed in a total volume of $25 \mu 1$. Crude nuclear extracts or chromatographic fractions from infected and mock-infected HeLa cells were routinely supplemented with uninfected HeLa cell nuclear extract to provide all of the transcription factors. Extract dialysis buffer was added as needed to keep the glycerol concentration constant. Template DNA concentrations were routinely $2-4 \mu \mathrm{g} / \mathrm{ml}$, or as indicated in the figure legends.

For the heat inactivation studies, DEAE-cellulose fractions derived from infected and mock-infected HeLa cells and containing equivalent protein concentrations were heated to $45^{\circ} \mathrm{C}$ for $10 \mathrm{~min}$. The fractions were placed on ice immediately. A fixed amount of nuclear extract from uninfected HeLa cells was then added to supply the basic transcription factors. The reaction cocktail, containing template DNA, nucleotides, [ $\left.{ }^{32} \mathrm{P}\right] \mathrm{GTP}$ and $\mathrm{MgCl}_{2}$, was added, and the samples were incubated at $30^{\circ} \mathrm{C}$, as described previously (Abmayr et al. 1985).

For the preincubation experiments, the DNA template (usually in $1 \mu \mathrm{l}$ ) was added to extract or fractions (usually 5- to $7.5-\mu \mathrm{l}$ in volume) in BC100 buffer [ $20 \% \mathrm{vol} / \mathrm{vol}$ glycerol, $20 \mathrm{mM}$ HEPES at (pH 7.9), $0.2 \mathrm{~mm}$ EDTA, and $100 \mathrm{~mm} \mathrm{KCl}$. These components were incubated at $30^{\circ} \mathrm{C}$ for various periods of time, as indicated in the figure legends, after which $\mathrm{MgCl}_{2}$, nucleoside triphosphates, and remaining transcription components were added, as appropriate. Individual conditions, fraction descriptions, and volumes were as indicated in the figure legends.

RNA samples were electrophoresed on $4.5 \%$ urea-acrylamide gels in Tris-borate buffer. Quantitation of transcription assays was done by densitometric scanning of autoradiograms.

\section{Acknowledgments}

We thank Wanda Cromlish for expert technical assis- 
tance, particularly in the experiments with nonspecific DNA competitors and deletion analysis, and Virginia Kozler for excellent assistance in the growth of cells and virus. This work was supported by grant CA 42567 from the National Cancer Institute to R.G.R. and by general support from the Pew Trusts to The Rockefeller University. J.L.W. was supported by National Institutes of Health (NIH) Fellowship GM11077. S.M.A. was supported by NIH Training Grant T32 A107233.

\section{References}

Abmayr, S.M. 1987. 'Stimulation of transcription by a viral immediate early protein: An in vitro study.' Ph.D thesis, Rockefeller University.

Abmayr, S.M., L.T. Feldman, and R.G. Roeder. 1985. In vitro stimulation of specific RNA polymerase II-mediated transcription by the pseudorabies virus immediate early protein. Cell 43: 821-829.

Berk, A.J. 1986. Adenovirus promoters and E1A transactivation. Annu. Rev. Genet. 20: 45-79.

Bradford, M.M. 1976. A rapid and positive method for the quantitation of microgram quantities of protein utilizing the principle of protein-dye binding. Anal. Biochem. 72: 248254.

Coen, D.M., S.P. Weinheimer, and S.L. McKnight. 1986. A genetic approach to promoter recognition during transinduction of viral gene expression. Science 234: 53-59.

Dignam, J.D., R.M. Lebovitz, and R.G. Roeder. 1983a. Accurate transcription initiation by RNA polymerase II in a soluble extract from isolated mammalian nuclei. Nucleic Acids Res. 11: $1475-1489$.

Dignam, J.D., P.L. Martin, B.S. Shastry, and R.G. Roeder. 1983b. Eukaryotic gene transcription with purified components. Methods Enzymol. 101: 582-598.

Feldman, L.T., M.J. Imperiale, and J.R. Nevins. 1982. Activation of early adenovirus transcription by the herpesvirus immediate early gene: Evidence for a common cellular control factor. Proc. Natl. Acad. Sci. 79: 4952-4956.

Ferguson, B., B. Krippl, O. Andrisani, N. Jones, H. Westphal, and M. Rosenberg. 1985. ElA 13 S and 12S mRNA products made in Escherichia coli both function as nucleus-localized transcription activators but do not directly bind DNA. Mol. Cell. Biol. 5: 2653-2661.

Fire, A., M. Samuels, and P.A. Sharp. 1984. Interactions between RNA polymerase II, factors, and template leading to accurate transcription. J. Biol. Chem. 259: 2509-2516.

Gaynor, R.B. and A.J. Berk. 1983. Cis-acting induction of adenovirus transcription. Cell 33: 683-693.

Hawley, D.K. and R.G. Roeder. 1985. Separation and partial characterization of three functional steps in transcription initiation by human RNA polymerase II. I. Biol. Chem. 260: $8163-8172$.

-1987. Functional steps in transcription initiation and reinitiation from the major late promoter in a $\mathrm{HeLa}$ nuclear extract. J. Biol. Chem. 262: 3452-3461.

Hoeffler, W.K., R. Kovelman, and R.G. Roeder. 1988. Activation of transcription factor IIIC by the adenovirus E1A protein. Cell (in press).

Hu, S.-L. and J.L. Manley. 1981. DNA sequence required for initiation of transcription in vitro from the major late promoter of adenovirus 2. Proc. Natl. Acad. Sci. 78: 820-824.

Ihara, S., L. Feldman, S. Watanabe, and T. Ben-Porat. 1983.
Characterization of the immediate-early functions of pseudorabies virus. Virology 131: 437-454.

Kingston, R.E., A.S. Baldwin, and P.A. Sharp. 1985. Transcription control by oncogenes. Cell 41: 3-5.

Knezetic, J.A. and D.S. Luse. 1986. The presence of nucleosomes on a DNA template prevents initiation by RNA polymerase II in vitro. Cell 45: 95-104.

Ko, J.L., B.L. Dalie, E. Goldman, and M.L. Harter. 1986. Adenovirus- 2 early region $1 \mathrm{~A}$ protein synthesized in Escherichia coli extracts indirectly associates with DNA. EMBO $J$. 5: $1645-1651$.

Kovesdi, I., R. Reichel, and J.R. Nevins. 1986a. E1A transcription induction: Enhanced binding of a factor to upstream promoter sequences. Science 231: 719-722.

- 1986b. Identification of cellular transcription factor involved in E1A trans-activation. Cell 45: 219-228.

Kristie, T.M. and B. Roizman. 1986a. ICP4, the major regulatory protein of herpes simplex virus type 1 , is stably and specifically associated with promoter-regulatory domains of genes and of selected other viral genes. Proc. Natl. Acad. Sci. 83: $3218-3222$.

1986b. DNA-binding site of major regulatory protein alpha-4 specifically associated with promoter-regulatory domains of alpha genes of herpes simplex virus type 1 . Proc. Natl. Acad. Sci. 83: 4700-4704.

Leong, K. and A.J. Berk. 1986. Adenovirus early region la protein increases the number of template molecules transcribed in cell-free extracts. Proc. Natl. Acad. Sci. 83: 5844-5848.

Matsui, T. 1987. Transcription of adenovirus 2 major late and peptide IX genes under conditions of in vitro nucleosome assembly. Mol. Cell. Biol. 7: 1401-1408.

Matsui, T., J. Segall, P.A. Weil, and R.G. Roeder. 1980. Multiple factors are required for accurate initiation of transcription by purified RNA polymerase II. I. Biol. Chem. 255: 1199211996.

Moran, E. and M.B. Mathews. 1987. Multiple functional domains in the adenovirus E1A gene. Cell 48: 177-178.

Muller, M. 1987. Binding of the herpes simplex virus immediate-early gene product ICP4 to its own transcription start site. J. Virol. 61: 858-865.

Nevins, J.R. 1981. Mechanism of activation of early viral transcription by the adenovirus ElA gene product. Cell 26: 213220.

Reinberg, D., M. Horikoshi, and R.G. Roeder. 1987. Factors involved in specific transcription by mammalian RNA polymerase II: Functional analysis of initiation factors IIA and IID and identification of a new factor operating downstream of the initiation site. J. Biol. Chem. 262: 3322-3330.

Sawadogo, M. and R.G. Roeder. 1984. Energy requirement for specific transcription initiation by the human RNA polymerase II system. J. Biol. Chem. 259: 5321-5326.

- 1985a. Factors involved in specific transcription by human RNA polymerase II: Analysis by a rapid and quantitative in vitro assay. Proc. Natl. Acad. Sci. 82: 4394-4398.

1985b. Interaction of a gene-specific transcription factor with the adenovirus major late promoter upstream of the TATA box region. Cell 43: 165-175.

Shenk, T., N. Jones, W. Colby, and D. Fowlkes. 1979. Functional analysis of Adenovirus- 5 host-range deletion mutants defective for transformation of rat embryo cells. Cold Spring Harbor Symp. Quant. Biol. 44: 367-375.

Slattery, E., J.D. Dignam, T. Matsui, and R.G. Roeder. 1983. Purification and analysis of a factor which suppresses nickinduced transcription by RNA polymerase II and its identity with poly(ADP-ribose) polymerase. I. Biol. Chem. 258: 5955-5959. 
Spangler, R., M. Bruner, B. Dalie, and M. Harter. 1987. Activation of adenovirus promoters by the adenovirus ElA protein in cell-free extracts. Science 237: 1044-1046.

Tremblay, M.L., S.P. Yee, R.H. Persson, S. Bacchetti, J.R. Smiley, and P.E. Branton. 1985. Activation and inhibition of expression of the 72,000-Da early protein of adenovirus type 5 in mouse cells constitutively expressing an immediate early protein of herpes simplex virus type 1. Virology 144: $35-45$.

Workman, J.L. and R.G. Roeder. 1987. Binding of transcription factor TFIID to the major late promoter during in vitro nucleosome assembly potentiates subsequent initiation by RNA polymerase II. Cell 51: 613-622.

Wu, L., D.S.E. Rosser, M.C. Schmidt, and A. Berk. 1987. A TATA box implicated in E1A transcriptional activation of a simple adenovirus 2 promoter. Nature 326: 512-515. 


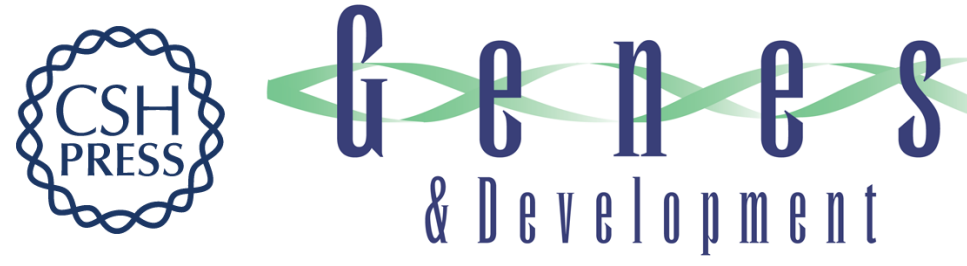

\section{The pseudorabies immediate early protein stimulates in vitro transcription by facilitating TFIID: promoter interactions.}

S M Abmayr, J L Workman and R G Roeder

Genes Dev. 1988, 2:

Access the most recent version at doi:10.1101/gad.2.5.542

References This article cites 37 articles, 19 of which can be accessed free at:

http://genesdev.cshlp.org/content/2/5/542.full.html\#ref-list-1

License

Email Alerting

Service

Receive free email alerts when new articles cite this article - sign up in the box at the top right corner of the article or click here.

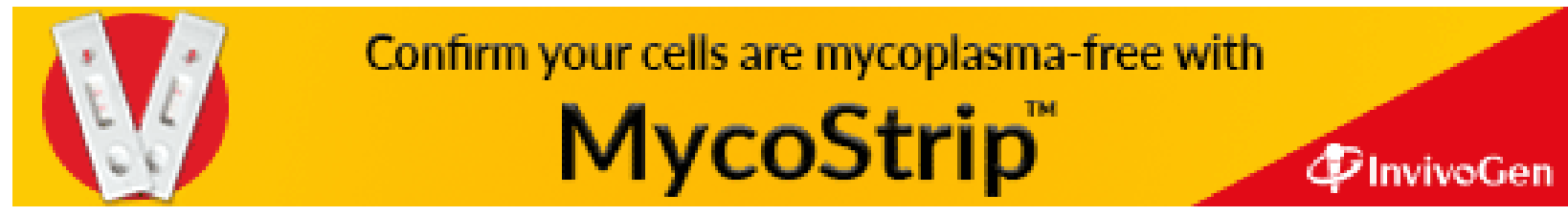

